\title{
Methylphenidate Increases Cortical Excitability via Activation of Alpha-2 Noradrenergic Receptors
}

\author{
Glenn D Andrews' and Antonieta Lavin*,I \\ 'Department of Physiology and Neuroscience, Medical University of South Carolina, Charleston, SC, USA
}

\begin{abstract}
Although methylphenidate (MPH), a catecholaminergic reuptake blocker, is prescribed for attention-deficit/hyperactivity disorder, there is a dearth of information regarding the cellular basis of its actions. To address this issue, we used whole-cell patch-clamp recordings to investigate the roles of various catecholamine receptors in MPH-induced changes in cortical neuron excitability. We bath-applied dopamine or noradrenaline receptor antagonists in combination with MPH to pyramidal cells located in deep layers of the infralimbic and prelimbic prefrontal cortices. Application of $\mathrm{MPH}(\mathrm{I} 0 \mu \mathrm{M})$ by itself increased cortical cell excitability in slices obtained from juvenile rats. This MPH-mediated increase in excitability was lost when catecholamines were depleted with reserpine prior to recording, demonstrating the requirement for a presynaptic monoamine component. Antagonist studies further revealed that stimulation of alpha-2 noradrenergic receptors mediates the MPH-induced increase in intrinsic excitability. Dopamine DI receptors played no observable role in the actions of $\mathrm{MPH}$. We therefore propose that MPH is acting to increase catecholaminergic tone in the PFC, and thereby increases cortical excitability by mediating the disinhibition of pyramidal cells through mechanisms that may include activation of alpha-2 adrenoreceptors located in interneurons.

Neuropsychopharmacology (2006) 31, 594-601. doi:I 0. I 038/sj.npp. I 3008 I 8; published online 6 July 2005
\end{abstract}

Keywords: prefrontal cortex; excitability; adrenergic receptors; dopaminergic receptors; reuptake blockers; electrophysiology

\section{INTRODUCTION}

The prefrontal cortex (PFC) is critically involved in cognitive processes underlying working memory (WM), attention, and inhibition of responses to nonrelevant stimuli (GoldmanRakic, 1996; Fuster, 2000). Studies in humans, non-human primates, and rats have shown that the PFC receives catecholaminergic inputs from the midbrain (Porrino and Goldman-Rakic, 1982; Levitt et al, 1984; Lewis et al, 1987; Lewis and Morrison, 1989; Miner et al, 2003) and a substantial amount of data supports the conclusion that dopamine (DA) and noradrenaline (NE) are involved in aspects of executive function (selective attention, response selection/control), as well as arousal (NE). These actions of DA and NE have been postulated to occur via their effects in the cortex. Although numerous studies have focused on the role of DA in the PFC (Sawaguchi et al, 1990; Arnsten et al, 1994, 1995; Yang and Seamans, 1996; Durstewitz et al, 1999; Lewis and O'Donnell, 2000; Lavin and Grace, 2001), there have been fewer studies analyzing the role of $\mathrm{NE}$ in modulating cortical activity relevant to cognitive performance.

*Correspondence: Dr A Lavin, Department of Physiology and Neuroscience, Medical University of South Carolina, 173 Ashley Ave, Room 403 BSB, Charleston, SC 29425, USA, Tel: + I 843792 6799, Fax: + I 843792 4423, E-mail: lavina@musc.edu

Received 3 February 2005; revised 12 April 2005; accepted 14 April 2005

Online publication: 3 June 2005 at http://www.acnp.org/citations/ Npp060305050074/default.pdf
Methylphenidate (MPH) is one of the most widely prescribed drugs for the treatment of attention-deficit hyperactive disorder (ADHD) (Hunt et al, 1984; Hunt, 1987), a condition that includes deficits in executive functions (WM and attention). MPH blocks the reuptake of both DA and NE (Carlsson et al, 1966; Axelrod, 1970; Ferris et al, 1972; Hendley et al, 1972; Ross, 1978; Seeman and Madras, 1998). Through this action, both acute systemic administration and iontophoretic application of $\mathrm{MPH}$ evoke increases in cortical activity (Lacroix and Ferron, 1988). Moreover, MPH improves WM performance in healthy subjects (Elliot et al, 1997; Mehta et al, 2000) and several studies have shown that MPH increases overall speed and accuracy of attentional process in normal adults (Strauss et al, 1984; Solanto, 1998). However, there is a dearth of data regarding the receptor mechanisms mediating the effects of MPH on cortical neurons. The purpose of the present study was to determine the effects of MPH on prefrontal cortical activity in slices from juvenile rats and to examine the receptors involved in the actions produced by $\mathrm{MPH}$. Or results show that MPH, via increases in catecholaminergic tone, increases cortical excitability acting through alpha-2 receptors.

\section{METHODS}

All procedures were carried out in accordance with the Guide for the Care and Use of Laboratory Animals 
published by the US Public Health Service, and was approved by the Medical University of South Carolina Animal Care and Use Committee.

\section{Preparation of Brain Slices}

Slices were prepared from juvenile (18-28 days) male Sprague-Dawley rats (Charles Rivers). The rats were deeply anesthetized with chloral hydrate $(400 \mathrm{mg} / \mathrm{kg})$, transcardially perfused with an oxygenated sucrose-substituted aCSF maintained at $1-5^{\circ} \mathrm{C}$ (in $\mathrm{mM}$ ): 200 sucrose, $1.9 \mathrm{KCl}, 1.2 \mathrm{Na}_{2} \mathrm{HPO}_{4}, 33 \mathrm{Na}_{2} \mathrm{HCO}_{3}, 6 \mathrm{MgCl}, 0.5 \mathrm{CaCl}_{2}, 10$ glucose, and 0.4 ascorbic acid. Rats were decapitated and the brain was rapidly removed. Sections $(350 \mu \mathrm{m})$ containing the PFC were obtained in the sucrose-substituted aCSF using a vibratome (Leica VT-1000S). The slices where then transferred to a holding chamber and incubated with oxygenated incubation buffer $(125 \mathrm{NaCl}, 2.5 \mathrm{KCl}, 1.2$ $\mathrm{NaH}_{2} \mathrm{PO}_{4}, 25 \mathrm{NaHCO}_{3}, 1 \mathrm{CaCl}, 4 \mathrm{MgCl}, 15$ sucrose, 10 dextrose, and 0.4 ascorbic acid) for at least $1 \mathrm{~h}$ at room temperature.

\section{Whole-Cell Recordings}

Individual slices were transferred to the recording chamber and neurons were visualized using an infrared upright microscope (Leica DMLFSA) equipped with a CCD video imaging camera (Hamamatsu C 2400). PFC pyramidal neurons were recognizable by their pyramidal-shaped cell body and the presence of a long apical dendrite projecting toward the pia. Current clamp recordings were performed using an Axopatch 200 B amplifier (Axon Instruments, Foster City, CA) with custom-made software. Electrodes were fabricated from borosilicate tubing (1.1 OD, Warner Instruments, Hamden, CT) using a horizontal Flaming/ Brown puller (model P-97). The electrodes had resistances of 5-12 M $\Omega$ when filled with (in $\mathrm{mM}$ ) 135 potassium gluconate, $3 \mathrm{KCl}, 2 \mathrm{MgCl}, 10 \mathrm{HEPES}, 1 \mathrm{EGTA}, 4 \mathrm{ATP}, 0.3$ GTP, 14 creatine phosphate, and $0.3 \%$ biocytin. The $\mathrm{pH}$ of the internal solution was 7.3. The signals were amplified and filtered at $10 \mathrm{kHz}$ in bridge-balance mode and acquired on a computer at sampling intervals of $20-100 \mu$ s through a National Instrument Board (BNC-2090). Series resistances (2-6 M $\Omega$ after 'break-in') were $85 \%$ compensated. No additional corrections were made for junction potential between bath and pipette solutions. The access resistance was continuously monitored during recording. The recordings were preformed at room temperature.

The input resistance (IR) was assessed for each cell during all pharmacological treatments by injecting a series of hyperpolarizing pulses in increments of $40 \mathrm{pA}$. The slope of the resulting curve yields the IR value.

\section{Excitability Measures}

In order to evaluate changes in intrinsic excitability, a series of constant current pulses (10-300 pA) were injected into the cell to determine a current level that on average evoked three action potentials under baseline conditions. Once this current was determined, the same current was then used for the rest of the experiment. Spikes were evoked every $30 \mathrm{~s}$ for 10 min during baseline recordings, drugs were then bath- applied and after $5 \mathrm{~min}$ measures were taken again every $30 \mathrm{~s}$ for at least 10 more minutes. The membrane potential was constantly held at the value obtained during baseline recordings.

In order to control for the effects of repetitive injection of current pulses during the bath-application of drugs, as well as for the simple effects of time passage in any drug effects, the stimulation protocol was repeated in the absence of any drugs. This protocol is called control-recovery.

\section{Drugs}

The drugs used were MPH ( 1 and $10 \mu \mathrm{M}$; Sigma), clonidine (10 $\mu \mathrm{M}$; Sigma), yohimbine ( 1 and $3 \mu \mathrm{M}$; Sigma), SCH 23390 (1-5 $\mu \mathrm{M}$; Sigma), and propanolol $(10 \mu \mathrm{M})$. These drugs were dissolved in aCSF and stored as concentrated stock solutions at $-20^{\circ} \mathrm{C}$. Prazosin $(1 \mu \mathrm{M})$ was dissolved in $80 \%$ ethanol. All drugs were bath-applied. In a subset of experiments, CPP $(10 \mu \mathrm{M})$, CNQX $(10 \mu \mathrm{M})$, and bicuculline $(10 \mu \mathrm{M})$ were added to the recording solution in order to prevent synaptic activity. The doses of MPH and clonidine used in the present experiments were selected following pilot experiments with dose-response curves (1-100 $\mu \mathrm{M}$ and $100 \mathrm{nM}-100 \mathrm{mM}$, respectively). For other drugs, the doses were selected based on an analysis of the literature.

\section{Catecholaminergic Depletion}

In order to test the assumption that the effects observed after MPH administration were mediated by an increase in catecholaminergic tone, five animals were pretreated with reserpine $(1.5 \mathrm{mg} / \mathrm{kg}$, i.p.) $1.5 \mathrm{~h}$ before euthanasia. After the brain was removed, the slices were incubated in buffer containing reserpine $(10-20 \mu \mathrm{M})$ until slices were transferred to the recording chamber. The significant degree of depletion of catecholamines produced by a similar treatment has been described previously (Heeringa and Abercrombie, 1995; Zimmer et al, 2002).

\section{Statistical Analysis}

In order to compare the effect of MPH on cortical excitability, paired Student's $t$-tests or repeated measures ANOVA (RM ANOVA) were used. Differences of alpha $\leqslant 0.05$ were considered significant. All the results are presented as mean $\pm \mathrm{SE}$.

\section{RESULTS}

A total of 125 cells were recorded in the infralimbic and prelimbic cortex. All neurons recorded were pyramidal cells, as identified by their electrophysiological and morphological characteristics under IRDC illumination and by subsequent biocytin labeling and immunohistochemistry. All the experiments were performed at the resting membrane potential values.

\section{Effects of MPH on Intrinsic Excitability}

The overall effect of MPH administration in all the cells tested in the PFC $(n=30)$ was a significant increase in intrinsic excitability ( $n=30$ cells; control: $3.9 \pm 0.3$ spikes/ 
pulse; MPH: $5.1 \pm 0.57$ spikes/pulse; $p<0.0007$, paired $t$-test; Figure 1 and Table 1). MPH administration decreased intrinsic excitability in only $2 / 30$ cells $(6.6 \%)$ and did not affect excitability in $33.3 \%$ of the cases (10/30 cells). The amplitude of the AHP and the IR were measured in a subgroup of 10 cells, and it was found that MPH administration did not produce a significant effect in any of these parameters.
Administration of $1 \mu \mathrm{M}$ MPH did not change cortical activity ( $n=10$; control: $2.8 \pm 0.3$ spikes/pulse; MPH: $2.7 \pm 0.61$ spikes/pulse; Table 1).

When the same protocol was repeated in the absence of $\mathrm{MPH}$, repetitive injections of current pulses did not increase cell excitability ( $n=5$; control $1: 4.1 \pm 0.9$ spikes/ pulse; control 2: $4.4 \pm 0.9$ spikes/pulse; Figure 1). Furthermore, these experiments demonstrate that prolonged
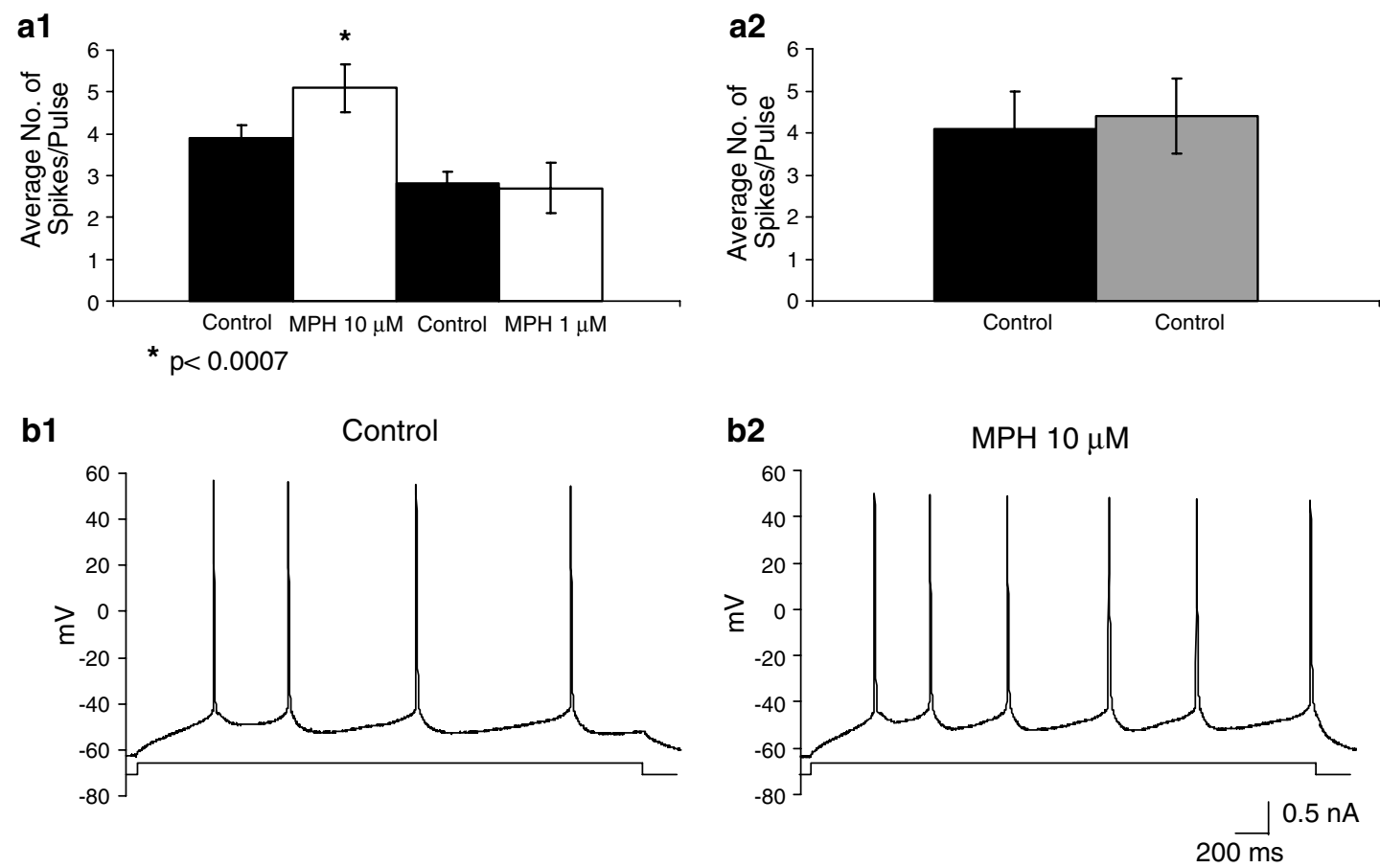

Figure I Bath-administration of MPH $(10 \mu \mathrm{M})$ results in significant increases in cortical excitability. (al) MPH mediates a significant increase in cortical excitability $(n=30, p<0.0007)$. In contrast, administration of lower concentrations of MPH $(I \mu M)$ did not evoke significant changes in cortical excitability The bar graphs depict the average number of spikes/pulse. (a2) Control-recovery experiments show that repetitive injection of current pulses does not induce an increase in the evoked activity of cortical cells. In addition, this experiment provides control for the temporal aspects of the experiments, demonstrating that the length of the recording does not affect intrinsic excitability. (b I) Representative traces of the average number of spikes evoked during control recordings and (b2) after $5 \mathrm{~min}$ of $\mathrm{MPH}(10 \mu \mathrm{M})$ administration.

Table I Effects of Specific DAergic and NErgic Drugs on Pyramidal Cell Properties

\begin{tabular}{|c|c|c|c|c|c|c|c|c|c|}
\hline & \multicolumn{3}{|c|}{$M P(m V)$} & \multicolumn{3}{|c|}{ IR (MS) } & \multicolumn{3}{|c|}{ Number of spikes/pulse } \\
\hline & Control & Trea & ment & Control & Trea & ment & Control & & atment \\
\hline Control-MPH $(|\mu M, n=| 0)$ & $71.3 \pm 0.8$ & & $71.2 \pm 0.4$ & $359.2 \pm 27.2$ & & $402.1 \pm 37.8$ & $2.8 \pm 0.3$ & & $2.7 \pm 0.6$ \\
\hline Control-MPH (reserpine) & $70.1 \pm 0.6$ & & $69.4 \pm 0.5$ & & & & $4.0 \pm 0.7$ & & $4.3 \pm 0.9$ \\
\hline Control-propanolol-MPH & $71.8 \pm 2.5$ & $71.8 \pm 2.1$ & $71.9 \pm 2.0$ & $423.4 \pm 41.1$ & $267 \pm 92.9$ & $420 \pm 50.8$ & $4.2 \pm 0.8$ & $5.2 \pm 1.5$ & $5.1 \pm 1.4$ \\
\hline Control-SKF 38390-MPH & $72.3 \pm 0.1$ & $72.6 \pm 0.2$ & $71.9 \pm 0.2$ & $345.1 \pm 64$ & $232 \pm 85$ & $327 \pm 81.1$ & $3.1 \pm 0.3$ & $3.7 \pm 0.7$ & $5.4 \pm 0.9 * * *$ \\
\hline Control-clonidine & $71.8 \pm 0.4$ & & $72.1 \pm 0.3$ & $575.3 \pm 56.9$ & & $418.9 \pm 62.7$ & $3.4 \pm 0.6$ & & $6.1 \pm 0.7 * * * *$ \\
\hline
\end{tabular}

Bold values indicate significant changes.

$* p<0.0007$.

*** $p<0.01$.

***** $p<0.03$

****** $p<0.000005$. 
recordings by themselves did not induce a change in cell activity.

\section{Effects of MPH in Catecholamine-Depleted Slices}

It is known that MPH increases the levels of catecholamines by blocking the NE reuptake transporter in the PFC (Axelrod, 1970; Carlsson et al, 1966; Ferris et al, 1972; Hendley et al, 1972; Ross, 1978; Sonders et al, 1997). Thus, the observed increases in cortical excitability elicited by MPH may result from an increased concentration on extracellular catecholamines. To test this hypothesis, animals were pretreated with reserpine, an inhibitor of the vesicular monoamine transporter. In slices harvested from animals pretreated with reserpine, MPH $(10 \mu \mathrm{M})$ failed to increase cortical excitability $(n=10$ cells; control: $4.0 \pm 0.7$ spikes/pulse; MPH: $4.3 \pm 0.9$ spikes/pulse; Figure 2 ). This result strongly suggests that the MPH-mediated increase in cortical excitability derives from an increase in the extracellular concentration of catecholamines. Reserpine treatment did not, however, affect the basic electrophysiological properties of pyramidal cells.

\section{Receptors Involved in the MPH-Mediated Increase in Excitability}

To identify the receptors underlying the MPH effect on cortical excitability, we tested the effects of specific NErgic or DAergic receptor antagonists. We tested the effects of bath-application of the specific alpha-1 antagonist prazosin $(1 \mu \mathrm{M})$, the specific alpha-2 antagonist yohimbine $(2 \mu \mathrm{M})$, the specific beta antagonist propanolol $(10 \mu \mathrm{M})$, and the specific DA D1 antagonist SCH $23390(1-5 \mu \mathrm{M})$. We tested only a specific DA D1 antagonist, but not a DA D2 antagonist, since only $\mathrm{D} 1$ receptor activation has been shown to increase cortical excitability in rat PFC slices (Yang and Seamans, 1996; Lavin and Grace, 2001).

\section{NErgic Antagonists}

Pretreatment with yohimbine $(2 \mu \mathrm{M})$ prevented the increase in excitability mediated by $\mathrm{MPH}(10 \mu \mathrm{M})(n=10$ cells;

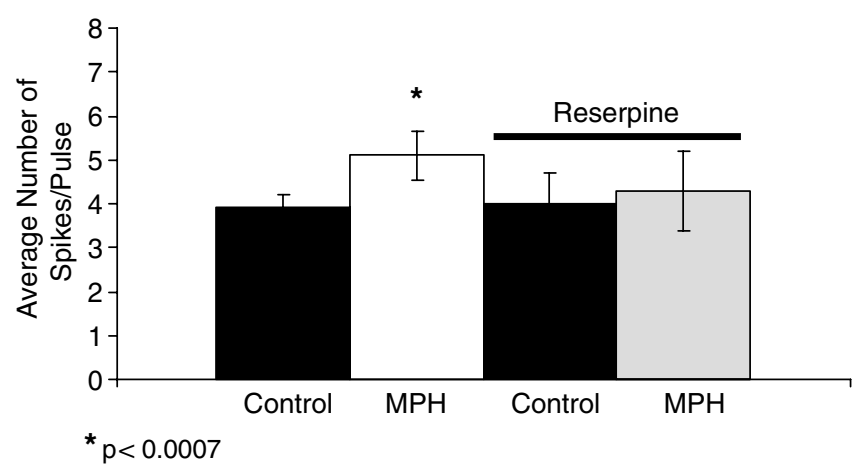

Figure $2 \mathrm{MPH}$ did not increase cortical excitability in reserpine-treated tissue. Bath-administration of $\mathrm{MPH}(10 \mu \mathrm{M})$ mediates significant increases in cortical excitability by increasing catecholaminergic tone. In contrast, if the tissue is pretreated with reserpine, MPH is unable to increase cortical excitability. The histogram represents the increases in average number of spikes/pulse. control: $3.4 \pm 0.4$ spikes/pulse; yohimbine: $3.7 \pm 0.5$ spikes/ pulse; MPH: $3.2 \pm 0.8$ spikes/pulse; $\mathrm{RM}$ ANOVA $\mathrm{F}(8,2)=$ $0.17, p<0.83$; Figure 3).

By contrast, pretreatment with the alpha-1 antagonist prazosin $(1 \mu \mathrm{M})$ did not prevent the MPH-mediated increase in excitability ( $n=10$ cells; control: $2.8 \pm 0.2$ spikes/pulse; prazosin: $3.8 \pm 0.5$ spikes/pulse; MPH: $4.9 \pm 0.9$ spikes/pulse; RM ANOVA, $\mathrm{F}(2,20)=3.78, p<0.04$; Figure 3). Indeed, Fisher's post hoc analysis indicates that $\mathrm{MPH}$ produces significant increases in cortical excitability $(p<0.01)$ relatively to control under conditions of alpha-1 receptor blockade.

Pretreatment with the beta antagonist propanolol $(10 \mu \mathrm{M})$ also failed to prevent the MPH-mediated increase in cortical excitability ( $n=10$; control: $4.2 \pm 0.8$ spikes/pulse; propanolol: $5.2 \pm 1.5$ spikes/pulse; MPH: $5.1 \pm 1.4$ spikes/pulse; RM ANOVA $F(2,16)=1.09, p<0.35$; Figure 3$)$.

\section{DAergic Antagonists}

Similarly, pretreatment of the cortical slices with SCH 23390 $(5 \mu \mathrm{M})$ did not prevent the MPH-mediated increase in excitability ( $n=10$; control: $2.8 \pm 0.3$ spikes/pulse; $\mathrm{SCH}$ 23390: $4.0 \pm 06$ spikes/pulse; $\mathrm{MPH}: 6.1 \pm 0.7$ spikes/pulse; RM ANOVA $\mathrm{F}(2,14)=9.7, p<0.02)$. Fisher's post hoc analysis shows that MPH produces a significant increase in excitability $(p<0.0006)$ when compared with control values under conditions of D1 receptor blockade (Figure 3).

\section{NE Agonists}

The experiments described above indicate that alpha-2 adrenoreceptors mediate the excitatory effects of MPH. In order to further test the effects of the alpha-2 receptors on cortical activity, the effects of a specific agonist of alpha-2 NErgic receptors (clonidine, $10 \mu \mathrm{M}$ ) were tested. Clonidine administration produced a significant increase in cortical excitability in $75 \%$ of the cells tested (15/20) (control: $3.4 \pm 0.6$ spikes/pulse; clonidine: $6.1 \pm 0.7$ spikes/pulse; paired $t$-test, $p<0.0006$; Figure 4).

\section{Role of Local Cortical Networks in the MPH-Mediated Increases in Excitability}

In order to investigate the role of the local network on the effects mediated by $\mathrm{MPH}$, recordings were performed in the presence of the glutamate and $\mathrm{GABA}_{\mathrm{A}}$ blockers, CNQX $(10 \mu \mathrm{M}), \mathrm{CPP}(10 \mu \mathrm{M})$, and bicuculline $(10 \mu \mathrm{M})$. In 10 pyramidal neurons tested under these conditions, MPH $(10 \mu \mathrm{M})$ administration did not increase intrinsic excitability (control: $2.3 \pm 0.3$ spikes/pulse; MPH: $2.0 \pm 0.4$ spikes/ pulse; Figure 5). This result suggests that the excitatory effects mediated by the increase in catecholamines resulting from MPH administration are indeed mediated through changes in cortical networks.

In summary, MPH administration significantly increased cortical excitability. When specific DA or NE receptor antagonists were administered prior to MPH, only alpha-2 blockade prevented the MPH-mediated increases in excitability. 
a1

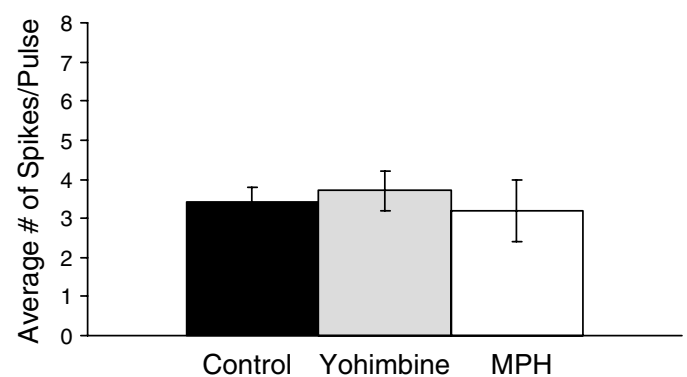

b1

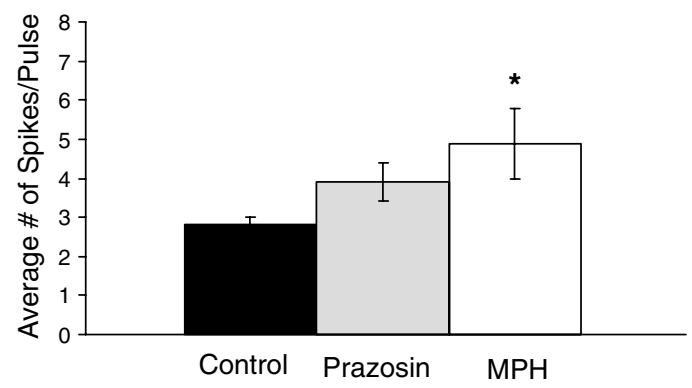

c

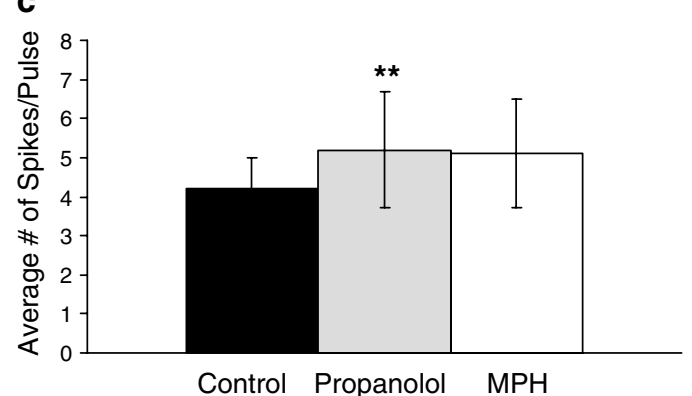

a2

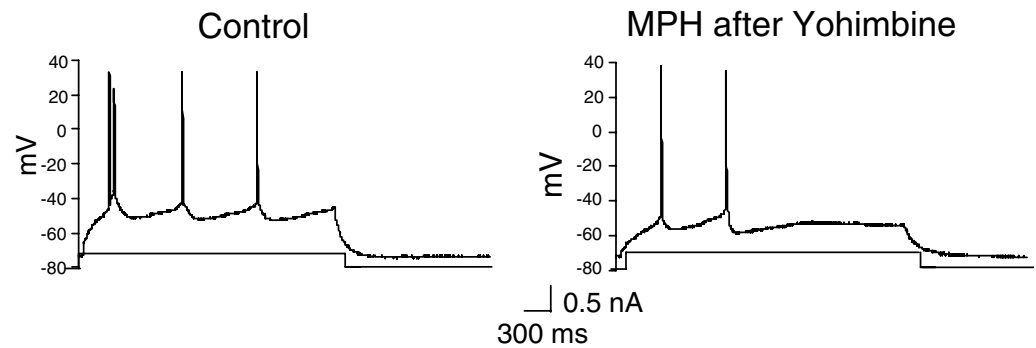

b2
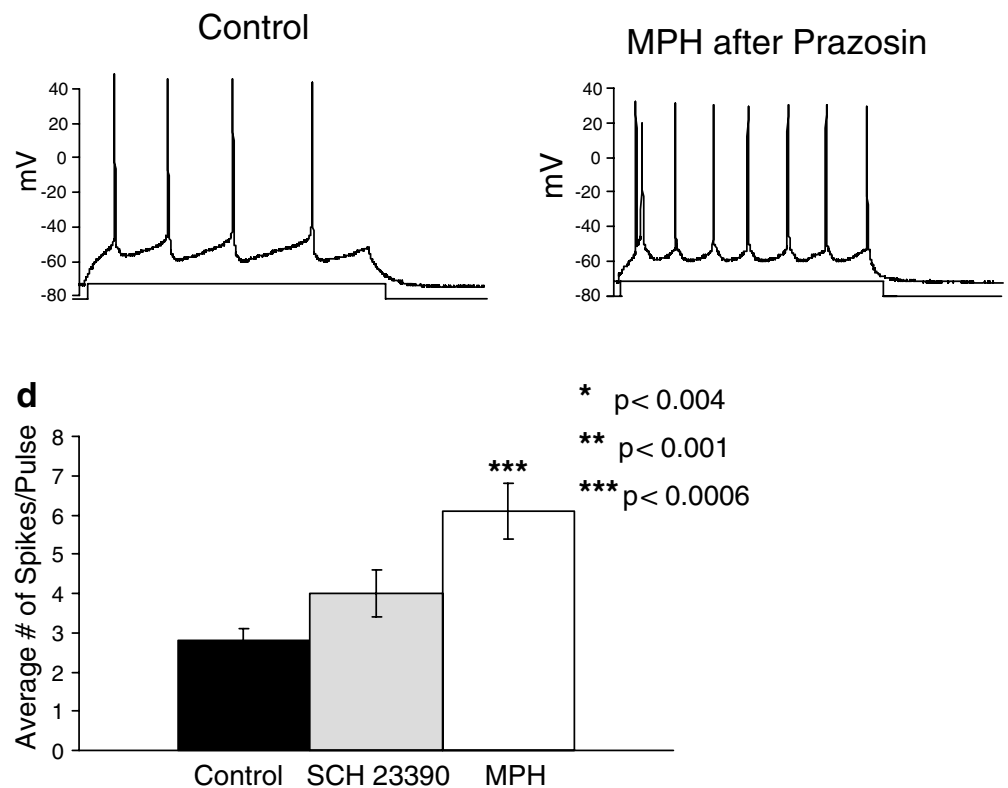

Figure 3 Alpha-2 antagonists block the MPH-mediated increases in cortical excitability. (al) The alpha-2 antagonist yohimbine (2 $\mu \mathrm{M})$ blocks the MPHmediated effects in cortical excitability. (a2) Representative traces showing the preventive effects of yohimbine administration. (bI) The alpha-I antagonist prazosin $(\mid \mu M)$ did not prevent the increase in excitability mediated by MPH $(10 \mu \mathrm{M}, p<0.004)$. (b2) Representative traces showing the MPH-mediated increases in cortical excitability following prazosin administration. (c) The beta antagonist propanolol ( $10 \mu \mathrm{M})$ induce a significant increase in cortical excitability $(p<0.00 \mathrm{I})$ that is sustained following MPH administration $(\mathrm{I} 0 \mu \mathrm{M})$. (d) The DA DI antagonist SCH $23390(5 \mu \mathrm{M})$ did not prevent the MPHmediated increases in cortical excitability.

\section{DISCUSSION}

We have shown that MPH mediates increases in excitability in cortical pyramidal neurons obtained from infant rats. The MPH-mediated increases were not observed when experiments were performed in reserpine-treated tissue, suggesting that the increase in cortical excitability is mediated by an increase in the concentration of catecholamines. Surprisingly, our results indicate that the mechanisms underlying the MPH modulation of cortical excitability involve activation of alpha- $2 \mathrm{NE}$ receptors.

\section{Effects of MPH on Cortical Excitability}

Our study reveals that MPH significantly increased excitability on cortical pyramidal neurons in normal animals. Moreover, our results suggest that the increase in cortical excitability is the result of MPH enhancing the concentra- tion of catecholamines in the synaptic cleft. Furthermore, the fact that specific NE antagonists induce increases in cortical excitability further suggests the presence of a catecholaminergic tone in the slice.

The specific alpha- 2 antagonist yohimbine was the only catecholaminergic antagonist that was able to suppress the excitatory effects of MPH. Alpha-2 receptors are located pre- and postsynaptically, and the alpha-2A subtype is most dense in the PFC and in the locus coeruleus (LC) (Aoki et al, 1994, 1998). Activation of alpha-2 receptors has been shown to hyperpolarize neurons through Gi proteins, as shown in the LC (Egan et al, 1983; Andrade and Aghajanian, 1985; Williams et al, 1985). This hyperpolarization is associated with increases in $\mathrm{K}^{+}$conductances and decreases in $\mathrm{Ca}^{2+}$ currents. Nonetheless, our results have shown that (1) the excitatory actions of MPH are mediated through alpha-2 receptors and (2) the alpha-2 agonist clonidine increased cortical excitability. 

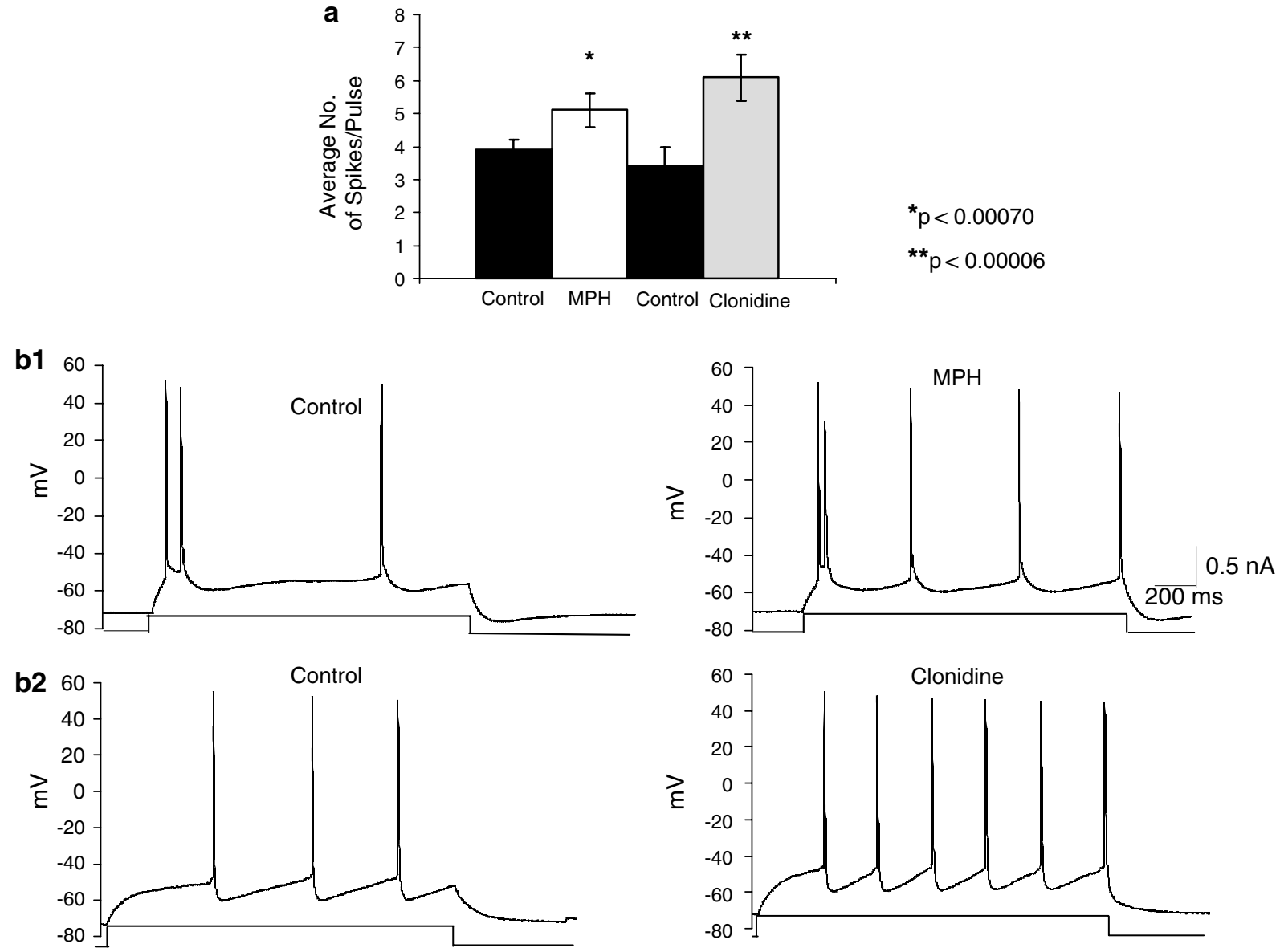

Figure 4 The specific alpha-2 agonist clonidine mimicked the increase in cortical excitability mediated by MPH. (a) The histogram indicates that both the reuptake blocker $\mathrm{MPH}$ and the specific alpha-2 agonist clonidine increased cortical excitability. (b I) Representative traces of the average number of spikes evoked during control recordings and following $\mathrm{MPH}(\mathrm{I} 0 \mu \mathrm{M})$ administration. (b2) Representative traces of the average number of spikes evoked during control recordings and following clonidine $(10 \mu \mathrm{M})$ administration.

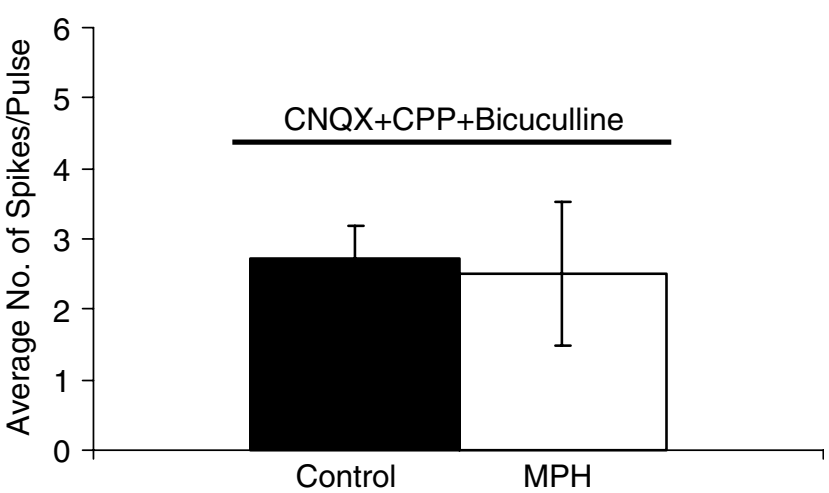

Figure 5 When the $\mathrm{GABA}_{A}$ and glutamate blockers, bicuculline $(10 \mu \mathrm{M}), \mathrm{CNQX}(10 \mu \mathrm{M})$, and CPP $(10 \mu \mathrm{M})$, were added to the bath, $\mathrm{MPH}$ administration did not increase cortical excitability.

How to explain this discrepancy? We hypothesize that $\mathrm{MPH}$ is increasing cortical activity by disinhibiting pyramidal neurons. That is, $\mathrm{MPH}$ is increasing the catecholaminergic tone in the slice, and as a consequence, higher concentrations of NE in the synaptic cleft now are able to activate pre- and postsynaptic receptors. Activation of presynaptic alpha-2 receptors in the slice will have minimal consequences; however, activation of postsynaptic alpha-2 NER located in interneurons could hyperpolarize GABA neurons and therefore disinhibit pyramidal cells. Indeed, our experiments with glutamate and GABA blockers suggest that the increases in excitability elicited by MPH administration are mediated through changes in local cortical networks. Moreover, preliminary whole-cell recordings of pyramidal cells in the presence of bicuculline indicate that administration of the alpha- 2 agonist clonidine fails to elicit increases in cell excitability (Lavin, 2004). Moreover, clonidine administration decreases activity of fast spiking interneurons (Lavin, 2004), indicating that at least part of the increase in excitability produced by clonidine was mediated by interneurons.

In summary, the present results support the hypothesis that MPH, by increasing the level of catecholamines in the cortex, produces a disinhibition of pyramidal cells and thereby an increase in cortical excitability. The presence of a catecholaminergic tone in the slice can be further suggested by our results showing that in tissue pretreated with reserpine, $\mathrm{MPH}$ failed to produce an increase in cortical excitability. Moreover, the MPH-mediated increases in excitability are mediated by activation of alpha-2 NER. 
Elliot et al (1997) have suggested that MPH enhances cognitive performance, WM, and sustained attention in normal volunteers. Moreover, Mehta and colleagues (2000) showed that the beneficial effects of MPH on WM in normal volunteers correlate with increased activity in the dorsolateral PFC and the parietal cortex. Thus, even in a normal system, MPH seems to improve attention and WM function. Therefore, it is tempting to speculate that by increasing cortical excitability, MPH optimizes cortical function including activity related with WM and attention. Moreover, by increasing cortical excitability, MPH could facilitate the response of neurons to strongly correlated synaptic inputs, therefore 'selecting' the activity of relevant stimuli over nonrelevant stimuli.

\section{ACKNOWLEDGEMENTS}

We thank Dr Sven Kroener and Dr David J Jentsch for the insightful discussions. This research was supported by National Institutes of Health Grant DA 14698 (AL).

\section{REFERENCES}

Andrade R, Aghajanian G (1985). Opiate and alpha-2 adrenoreceptor-induced hyperpolarizations of locus coeruleus neurons in brain slices: reversal by cyclic adenosine $3^{\prime}-5^{\prime}$-monophosphate analogues. J Neurosci 5: 2359-2364.

Aoki C, Go C-G, Venkatesan C, Kurose H (1994). Perikayral and synaptic localization of alpha-2A-adrenrgic receptor-like immunoreactivity. Brain Res 650: 181-204.

Aoki C, Venkatesan C, Go C-G, Forman R, Kurose H (1998). Cellular and subcellular sites for noradrenergic action in the monkey dorsolateral prefrontal cortex as revealed by immunocytochemical localization of noradrenergic receptors and axons. Cereb Cortex 8: 269-277.

Arnsten AF, Cai JX, Steere JC, Goldman-Rakic PS (1995). Dopamine D2 receptor mechanisms contribute to age-related cognitive decline: the effects of quinpirole on memory and motor performance in monkeys. J Neurosci 15: 3429-3439.

Arnsten AF, Cai JX, Murphy BL, Goldman-Rakic PS (1994). Dopamine D1 receptor mechanisms in the cognitive performance of young adult and aged monkeys. Psychopharmacology 116: $143-151$.

Axelrod J (1970). Amphetamine: metabolism, physiological disposition and its effects on catcholamine storage. In: Costa E, Garattini S (eds). Amphetamine and Related Compounds. Raven: New York. pp 207-216.

Carlsson A, Fuxe K, Hamberger B, Linqvist M (1966). Biochemical and histochemical studies on the effects of imipramine-like drugs and (+)-amphetamine on central and peripheral catecholamine neurons. Acta Physiol Scand 67: 481-497.

Durstewitz D, Kelc M, Gunturkun O (1999). A neurocomputational theory of the dopaminergic modulation of working memory functions. J Neurosci 19: 2807-2822.

Egan TM, Henderson G, North RA, Williams JT (1983). Noradrenaline-mediated synaptic inhibition in rat locus coeruleus neurones. J Physiol London 345: 477-488.

Elliot R, Sahakian BJ, Matthews K, Bannerjea A, Rimmer J, Robbins TW (1997). Effects of methylphenidate on spatial working memory and planning in healthy young adults. Psyhcopharmacology (Berl) 131: 190-206.

Ferris RM, Tang FLM, Maxwell RA (1972). A comparison of the capacities of isomers of amphetamine, deoxypipradrol and methylphenidate to inhibit the uptake of tritriated catecholamine into rat cerebral cortex slices, synaptosomal preparation of rat cerebral cortex, hypothalamus and striatum and into adrenergic nerves of rabbit aorta. J Pharmacol Exp Ther 181: 407-416.

Fuster JM (2000). Prefrontal neurons in networks of executive memory. Brain Res Bull 52: 331-336.

Goldman-Rakic P (1996). Regional and cellular fractionation of working memory. Proc Natl Acad Sci USA 93: 13473-13480.

Heeringa MJ, Abercrombie ED (1995). Biochemistry of somatodendritic dopamine release in substantia nigra: an in vivo comparison with striatal dopamine release. J Neurochem 65: 192-200.

Hendley ED, Snyder SH, Fauley JJ, LaPidus JB (1972). Stereoselectivity of catecholamine uptake by brain synaptosomes: studies with ephedrine, methylphenidate and phenyl-2-piperidyl carbinol. J Pharmacol Exp Ther 183: 103-116.

Hunt RD (1987). Treatment effects of oral and transdermal clonidine in relation to methylphenidate: an open pilot study in ADD-H. Psychopharmacol Bull 23: 111-114.

Hunt RD, Cihen DJ, Anderson G, Clark L (1984). Possible change in noradrenergic receptor sensitivity following methylphenidate treatment: growth hormone and MHPG response to clonidine challenge in children with attention deficit disorder and hyperactivity. Life Sci 35: 558-897.

Lacroix D, Ferron A (1988). Electrophysiological effects of methylphenidate on the coeruleo-cortical noradrenergic system in the rat. Eur J Pharmacol 149: 277-285.

Lavin A (2004). Alpha 2 agonists increase cortical excitability. Soc Neurosci (abstract \# 45.14).

Lavin A, Grace AA (2001). Stimulation of D1-type dopamine receptors enhances excitability in prefrontal cortical pyramidal neurons in a state-dependent manner. Neuroscience 104: 335-346.

Levitt P, Rakic P, Goldman-Rakic P (1984). Region-specific distribution of catecholamine afferents in primate cerebral cortex: a fluorescence histochemical analysis. J Comp Neurol 227: $23-36$.

Lewis BL, O’Donnell P (2000). Ventral tegmental area afferents to the prefrontal cortex maintain membrane potential 'up' states in pyramidal neurons via $\mathrm{D}(1)$ dopamine receptors. Cereb Cortex 10: $1168-1175$.

Lewis DA, Campbell MJ, Foote SL, Goldstein M, Morrison JH (1987). The distribution of tyrosine hidroxylase-immunoreactive fibers in primate neocortex is widespread but regionally specific. J Neurosci 7: 279-290.

Lewis DA, Morrison JH (1989). The noradrenergic innervation of monkey prefrontal cortex: a dopamine beta hydroxylase immunohistochemical study. J Comp Neurol 282: 317-330.

Mehta MA, Owen AM, Sahakian BK, Mavaddat N, Pockard JD, Robbins TW (2000). Methylphenidate enhances working memory by modulating discrete frontal and parietal lobe regions in the human brain. J Neurosci 20: 1-6.

Miner LH, Schoeter S, Blakeley RD, Sesack SR (2003). Ultrastructural localization of the norepinephrine transporter in superficial and deep layers of the rat prelimbic prefrontal cortex and its spatial relationship to probably dopamine terminals. $J$ Comp Neurol 467: 478-494.

Porrino LJ, Goldman-Rakic PS (1982). Brainstem innervation of prefrontal and anterior cingulated cortex in the rhesus monkey revealed by retrograde transport of HRP. J Comp Neurol 205: 63-76.

Ross SB (1978). Antagonism by methylphenidate of the stereotyped behavior produced by $(+)$ amphetamine in reserpinized rats. J Pharm Pharmacol 30: 253-254.

Sawaguchi T, Matsumura M, Kubota K (1990). Effects of dopamine antagonists on neuronal activity related to a delayed response task in monkey prefrontal cortex. J Neurophysiol 63: 1401-1412.

Seeman P, Madras BK (1998). Anti-hyperactivity medication: methylphenidate and amphetamine. Mol Psychiatry 3: 386-393. 
Solanto MV (1998). Neuropsychopharmacological mechanisms of stimulant drug action in attention-deficit hyperactivity disorder: a review and integration. Behav Brain Res 94: 127-152.

Sonders MS, Zhu S-J, Zahniser NR, Kavanaugh MP, Amara SG (1997). Multiple ionic conductances of the human dopamine transporter: the actions of dopamine and psychostimulants. $J$ Neurosci 17: 960-974.

Strauss J, Lewis JL, Klorman R, Peloquin LJ, Perlmutter RA, Salzman LF (1984). Effects of methylphenidate in young adults' performance and event-related potentials in a vigilance and paired-associated learning test. Psychophysiology 21: 609-621.
Williams JT, Henderson G, North RA (1985). Characterization of alpha-2-adrenorecepotrs which increase potassium conductance in rat locus coeruleus neurons. Neuroscience 14: 95-100.

Yang CR, Seamans JK (1996). Dopamine D1 receptor actions in layers V-VI rat prefrontal cortex neurons in vitro: modulation of dendritic-somatic signal integration. J Neurosci 16: 1922-1935.

Zimmer L, Vancassel S, Cantagrel S, Breton P, Delamanche S, Guilloteau D et al (2002). The dopamine mesocortcolimbic pathway is affected by deficiency in $n-3$ polyunsaturated fatty acids. Am J Clin Nutr 75: 662-667. 